\title{
Application of Model Display Technology in Multimedia Teaching of Ecological Architecture Course
}

\author{
http://dx.doi.org/10.3991/ijet.v11i09.6121 \\ Liming $\mathrm{Bo}^{1}$, Kanhua $\mathrm{Yu}^{2}$ \\ ${ }^{1}$ Wuhan University, Wuhan, China \\ ${ }^{2}$ Chang'an University, Xi'an, China
}

\begin{abstract}
-as building information model technology becomes increasingly developed, building information model technology is increasingly introduced in modern construction engineering project design, and good effect has been gained. Based on the above background, this paper applied building information model technology to develop a building information model technology image display system. This system has such functions as teletransmission, 3D display, plane display and interactive demonstration. Based on $B / S$ architecture, this system can achieve teletransmission display between building plane image and $3 \mathrm{D}$ image. On this basis, contrastive teaching research was adopted to apply the system in teaching Ecological Architecture Course of architectural engineering specialty. The results show that the combination of model display technology and multimedia teaching system can improve courseware display effect and transmission efficiency and then significantly promote course teaching effect.
\end{abstract}

Index Terms-model display technology, building model image display system, Ecological Architecture Course, teaching experiment

\section{INTRODUCTION}

Building model image display technology is a new image technology [1] which is based on the achievements of information and digitization technologies and displays plane or 3D effect of building physical model through optical sensing [2], digit arithmetic and information processing process. This technology came into being with the birth of building information model (BIM). In recent years, building model image display technology has been more and more applied in the initial design of construction project and has become an important assistive technology of construction project designers and managers to observe project model, modify design scheme and offer information display [3].

Based on the above background, a scholar associated building model image technology and modern architectural engineering teaching and discussed the feasibility of combining the two to carry out educational reform. Fonseca [4] proposed 3D models and presentation of architectural projects through students majoring in architecture and building engineering, and found that this system could improve academic records of students majoring in architecture. Tong [5] deeply explored the application of real 3D display technology in real-time manifestation of building landscape environment and indicated that real 3D display technology is an important branch of building model image display technology and has great significance for architectural engineering teaching reform. Dong [6] mainly studied the application of virtual reality display technology in building courses. With the above technology, he constructed a model image display scene so that students could learn and exchange in a natural way in the scene. Ye studied the application of 3D laser scanning technology in ancient building surveying and mapping. The results indicate that this technology can meet the requirements of ancient building surveying and mapping result making. Besides, the advantages of this technology and traditional technology in surveying and mapping different ancient buildings were summarized. The research has certain reference significance for ancient building surveying and mapping [7].

It is found through looking up pertinent literatures that, most researches of scholars on the application of building model image technology in course teaching are in the exploration stage, and fail to form detailed theoretical and practical application system. Thus, the practical applications of existing researches are not deep enough. Besides, the research achievements of combining building model display technology with Ecological Architecture Course teaching are few. Therefore, exploring a new teaching mode based on building model image display technology has important significance for teaching innovation and reform of college architectural engineering specialty. Meanwhile, relevant courseware producers mostly depend on the planar graph in existing building model technology for teaching [8]. For example, design drawing and construction drawing cannot fully display 3D image if building model. On this basis, this paper designed and developed a building model image display system. The system has such functions as teletransmission, 3D display, plane display and interactive demonstration as well as strong visual property, dynamic sense and teaching advancement.

\section{DESIGN OVERVIEW OF MOdEL IMAGE DisPlay SYSTEM}

\section{A. Design thought}

The model image display system designed in this paper is an intelligent model imaging display system based on BIM. This system adopts $\mathrm{B} / \mathrm{S}$ architecture and comprehensively applies information technology [9], digital technique, intelligent imaging technology [10] and wireless transmission technology [11]. Through the mode of sending imaging signal from the server to the terminal, a server maps plane or 3D graphs of building model to 


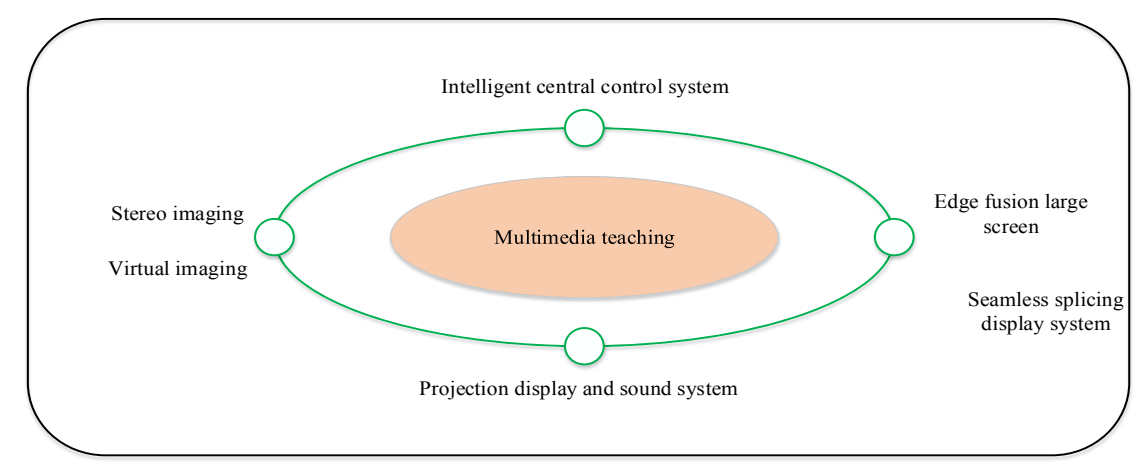

Figure 1. Mode diagram of multimedia system based on model display technology

multiple terminals. In the specific application, the controller of server can adjust the shape, color and luminosity of display model. The application personnel of terminal can view imaged building model or send text and picture information to the server, and communicate with the controller of server through human-computer interaction. Hence, the whole system can not just achieve model imaging display function, but can achieve interactive demonstration function. Compared with traditional building multimedia display system, this system improves display reliability, interactivity and advancement. Based on the above design thought, overall design diagram of this system is shown in figure 1 and figure 2.

As shown in figure 2, this system adopts standard B/S architecture, and is composed of 1 server and $\mathrm{N}$ clients. The two achieve communication through wireless transmission technology. Each client has a large display screen and thus can offer multiple online and timely interactive demonstration scenes for the persons with different learning, observation and visiting needs. In this way, the system not just owns building model display function, but also has multi-scene interactive demonstration function.

\section{B. Composition modules}

Based on the above design thought, this system is divided into 2 modules and designed with $\mathrm{B} / \mathrm{S}$ architecture. Information hardware layout of system is constructed. In practical work, each module focuses on the core function of building model image display to operate. Figure 3 shows the composition modules of this system.

As shown in figure 3, this system is mainly composed of server and client. The server module and client module contain several sub-modules. Each module is correlated to complete dynamic display function of models. The detailed module functions are as follows:

(1) Image modulation module: picture or building model image is modulated into transmission signals.

(2) Wireless module: $802.11 \mathrm{n}$ wireless transmission technology is adopted to achieve communication between the server and client.

(3) Server setting module: used to set the functions of server, such as system time and database data taking.

(4) Database module: used to store building model materials needed by course teaching.

(5) Image demodulation module: model image signal sent by the server is demodulated to practical $3 \mathrm{D}$ or plane graph signal.

(6) Image display module: it can carry out adaptive adjustment of model graph color, position, perspective de-

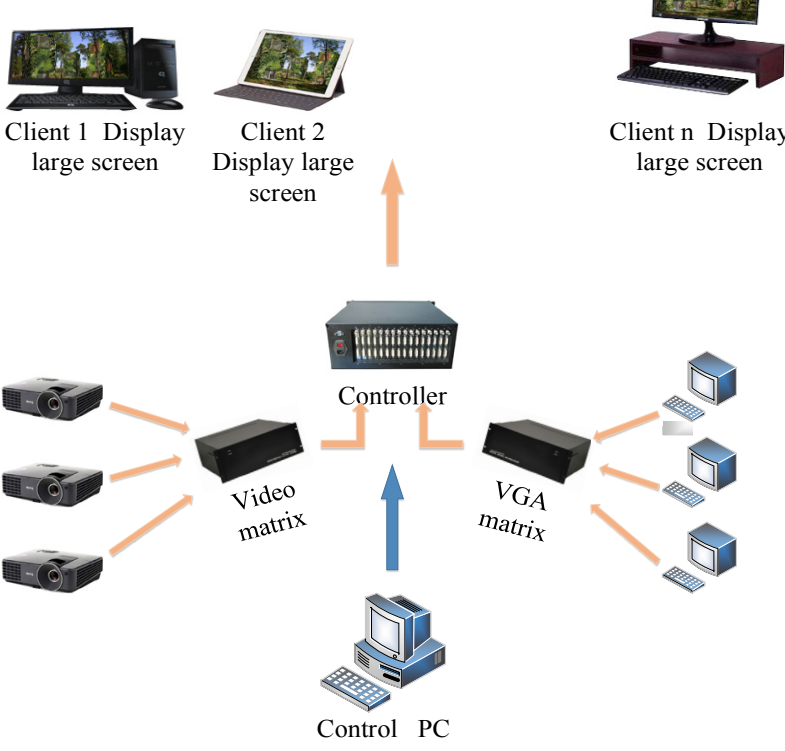

Figure 2. Overall design diagram of model display technology system

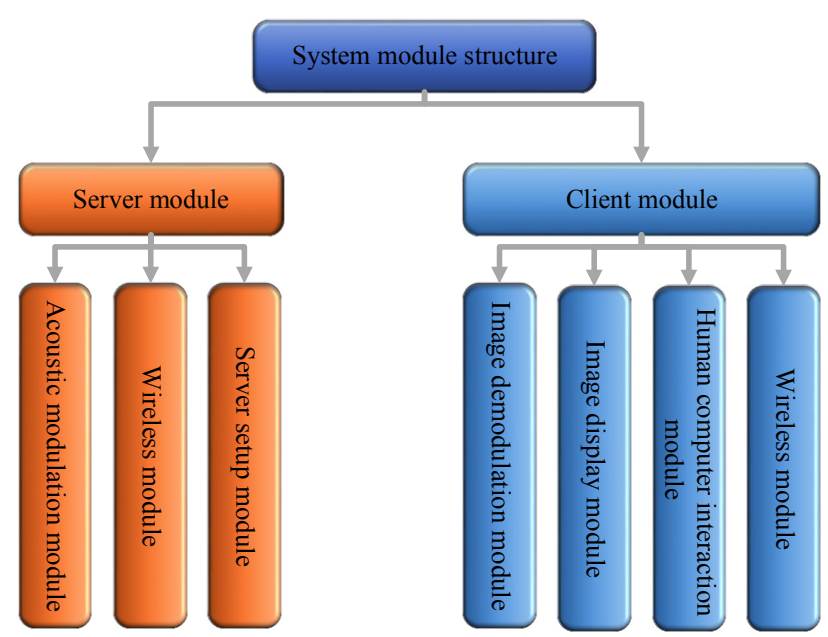

Figure 3. Composition diagram multimedia system based on display technology

gree, luminance and gray level and project the graph on the large scene of each client.

(7) Human-computer interaction module: it is designed with touch screen control. With this module, the client users can communicate with server users in the form of voice and text. 


\section{Working process}

In the specific teaching application, the working process of this system is shown in figure 4.

With this system, the teacher can conduct remote interactive demonstration with students on each client through the server. Students on the client can view vivid dynamic graphs of building model through $3 \mathrm{D}$ and plane model image transmission and display functions of the system. If students encounter difficult knowledge points, they may online communicate with the teacher at the server through the touch screen interface at the client. Compared with traditional multimedia image system, this system has better convenience, interactivity, entertainment and teaching efficiency, because it introduces high-speed wireless function.

\section{ANALYSIS OF TEACHING EXPERIMENT}

\section{A. Knowledge preparation}

This teaching experiment took Ecological Architecture Course of college architectural engineering specialty for example. Before class, knowledge preparation links were required. Firstly, the teacher guided students to know the contents of building model image display technology, ecological architecture overview and architectural mechanics. Secondly, the teacher displayed some global typical cases of ecological architecture through traditional multimedia equipment, such as Green Energy Center in Korea, Chongqing Huanshan Central Business District and Dubai Pyramid Sustainable City. In this way, the teaching objects could construct basic cognition of ecological architecture.

\section{B. Teaching objects}

The students in Class (1) and Class (2) of 2015 architectural engineering specialty were chosen as the objects. Each class included 45 students, and both classes had no significant statistical difference in the age, gender and learning ability $(\mathrm{P}>0.05)$. In the specific teaching experiment, Class (1) served as the control class, and Class (2) served as the experimental class.

\section{Experimental design scheme}

In the teaching, Ecological Architecture was chosen as the course content, including 72 class hours. The course was composed of theory and practice. To highlight teaching value of this model display system, this system was applied for the experimental class, while traditional multimedia equipment was used for the control class. After the course ended, practice and theory examination scores of both classes were collected and recorded, and the teaching effects were compared.

\section{Statistical method}

SPSS13.0 software was applied for sample analysis of each learning index. $\mathrm{P}<0.05$ means the difference has statistical significance. Meanwhile, EXCEL was adopted to make graphs for corresponding statistical data and make teaching evaluation results clear at a glance.

\section{E. Method}

\section{1) Control class}

During teaching the control class, the teacher implemented teaching activity with traditional theory teaching method. The specific teaching mode was as follows: blackboard and multimedia courseware served as the teaching carriers, and teaching by personal example as well as verbal instruction, PPT presentation, question answering in classroom and assignment arrangement were comprehensive applied to implement teaching.

\section{2) Experimental class}

Concept teaching. To make teaching pertinence stronger, the teacher needed to adopt 1 class hour to teach basic concepts of Ecological Architecture and help them establish basic cognition. For example, for Chapter 1 - Concept of Ecological Architecture, the teacher adopted traditional multimedia equipment to explain relevant concepts and gathered questions of students. Meanwhile, the teacher explained the operation method of model display system client. Corresponding teaching multimedia courseware data are as figure 5 and 6 .

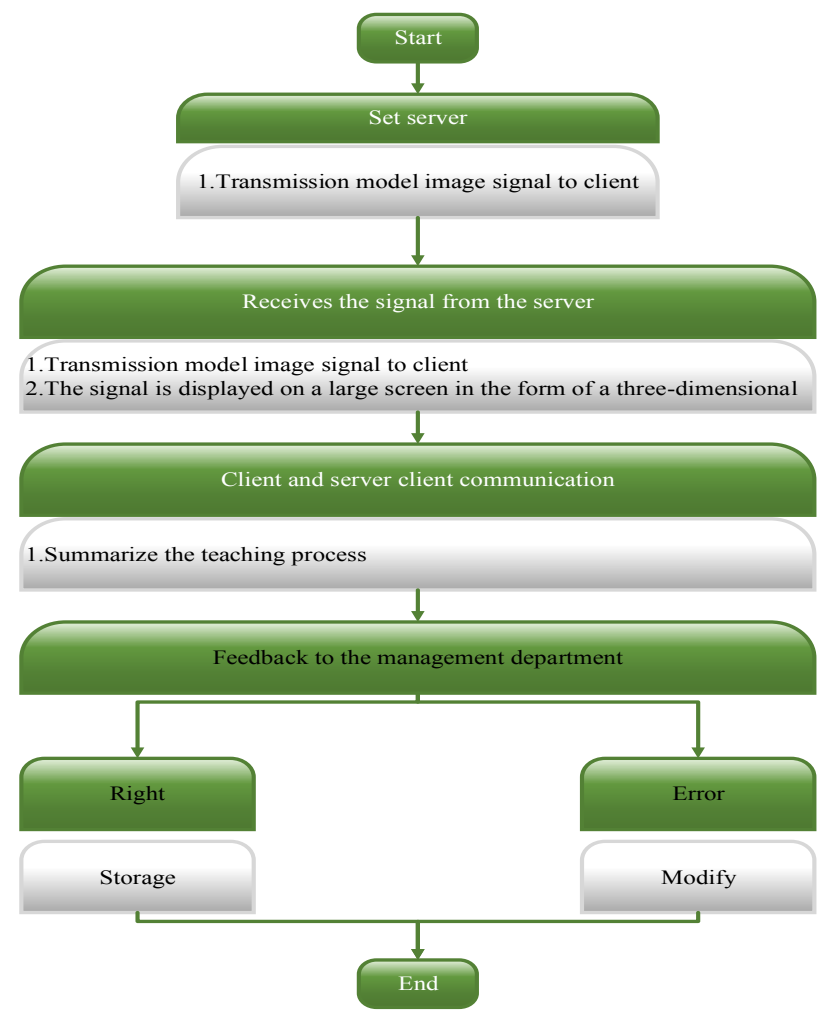

Figure 4. Operation process diagram of multimedia system based on display technology

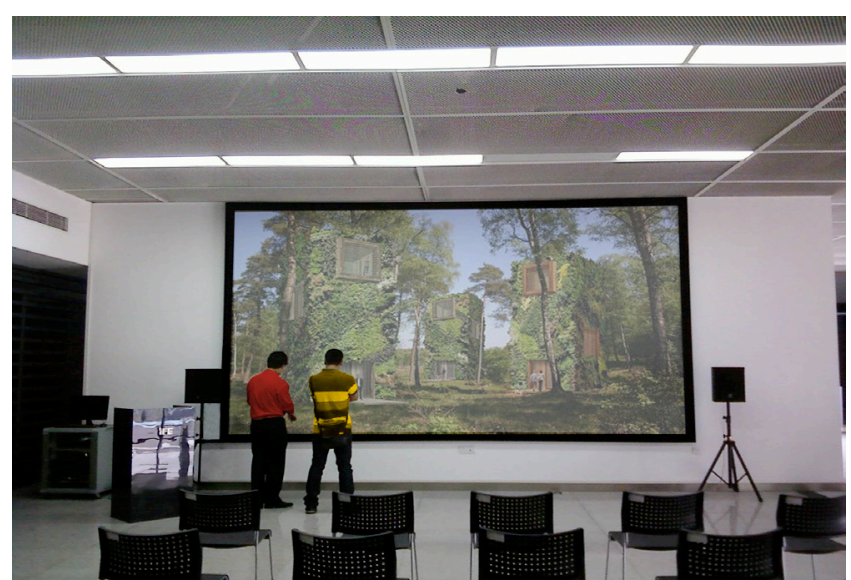

Figure 5. Multimedia data of Concept of Ecological Architecture 


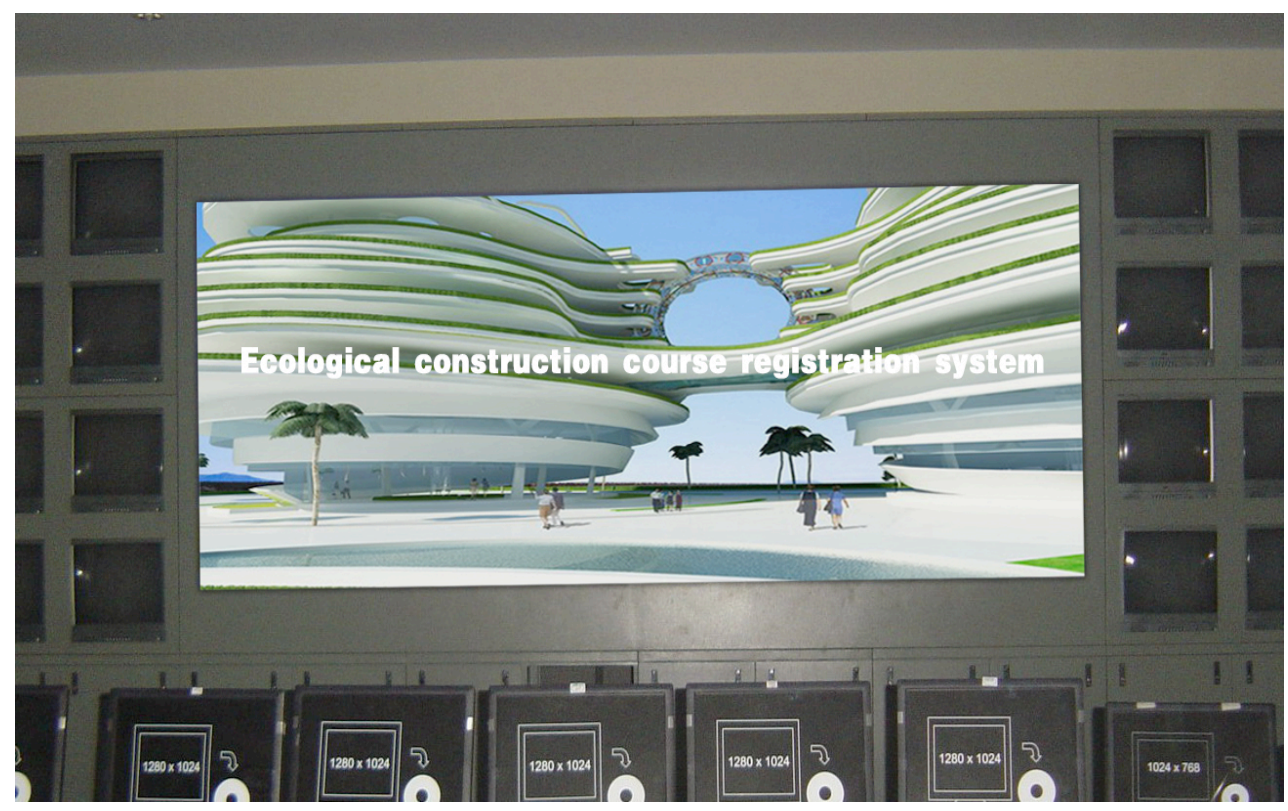

Figure 6. Teaching pictures played by building model display system

Viewing interaction teaching. After helping all students establish cognition, the teacher led students to enter "building model display system training room" and grouped students according to their question types. A client training viewing room was arranged for each group. The teacher set well at the server and transmitted corresponding ecological architecture model image from the database as required by students, while students interacted with the teacher at the server through the touch screen at the client. In this way, "one-to-many" efficient teaching mode was established. With the system, the teacher could answer questions of each group in a convenient, fast and relaxing way.

Summarization and discussion link. After each group completed learning, the teacher utilized online interaction function of the system to collect learning feelings of each group, and discussed theory and practice learning experience with students on the platform. Finally, the teacher shared plane and $3 \mathrm{D}$ views of models to the server, and students could download learning materials by the client for review.

\section{TEACHING RESULTS}

\section{A. Teaching results}

After the teaching for 72 class hours, the teacher prepared Standard for Grading Practice Examination Scores, gathered and sorted various learning indexes of both classes, and compared teaching effects. $\mathrm{P}<0.05$ marked the results have statistical difference. The detailed statistic results are shown in Table I.

Through Table I, the teacher conducted statistics of practice examination scores of both classes and sorted theory examination scores of both classes. The detailed data are as table II.

It is known from Table I and Table II that, the data of experimental class are significantly superior to the data of control class regardless of theory examination score and practice examination score $(\mathrm{P}<0.05)$. Thus, statistical data of teaching contrast experiment have statistical difference, and the data are real and effective.

TABLE I.

STANDARD FOR GRADING PRACTICE EXAMINATION SCORES

\begin{tabular}{|l|l|c|}
\hline \multicolumn{1}{|c|}{ Content } & \multicolumn{1}{c|}{ Detailed standard } & Score \\
\hline Before-class learning ability (20 scores) & Before-class self-study enthusiasm and effect & 20 \\
\hline Model viewing and imagination power & View the model on the site and construct the model; thought activeness & 20 \\
\hline Manual modeling ability & The ability to apply design software to design ecological architecture model & 20 \\
\hline Ecological architecture idea construction level & The level of mastering ecological architecture idea after innovation ability ends & 20 \\
\hline Innovation ability & Quantity and quality of innovation practice for Ecological architecture modeling & 20 \\
\hline
\end{tabular}

TABLE II. EXAMINATION SCORE COMPARISON OF CONTROL CLASS AND EXPERIMENTAL CLASS (SCORE, , X+S)

\begin{tabular}{|l|c|c|}
\hline \multicolumn{1}{|c|}{ Class } & Theory examination score & Practice examination score \\
\hline Experimental class & $95.17+4.23$ & $90.22+6.78$ \\
\hline Control class & $69.56+3.65$ & $72.76+4.56$ \\
\hline $\mathrm{t}$ & -2.654 & -3.331 \\
\hline $\mathrm{p}$ & 0.002 & 0.001 \\
\hline
\end{tabular}




\section{B. Discussions}

Ecological Architecture is an emerging course of college architectural engineering specialty. This course aims to impart healthy, energy-saving and green architectural design idea to students and show feasibility and value of ecological architectural design and construction through observation of classical buildings. Under traditional mode, most teachers get used to applying multimedia equipment to design teaching process. In such mode, it is hard to really mobilize students' learning initiative. Multimedia equipment can only display plane image of ecological architectural model and cannot show 3D image or achieve effective exchange and interaction. In addition, when students put forward questions, it is difficult for a teacher to answer the questions of all students. Thus, question answering link often makes the teacher caught in the plight, which seriously affects teaching quality.

With building model image display system, the teacher can not merely show plane and 3D view of ecological architectural model, but also can establish wireless communication channel with students through $\mathrm{B} / \mathrm{S}$ architecture. The whole teaching is similar to communication on internet. Exchange between the teacher and students can be completed through pure text, picture and video. Compared with expounding something mechanically and answering questions in classroom, the efficiency naturally improves, and the effect is more vivid. The academic performance of experimental class is significantly better than that of control class. This indicates that this system has actual effects on Ecological Architecture teaching.

\section{CONCLUSION}

This paper designed a building model image display system and applied this system in Ecological Architecture teaching. The comparative study shows that visual property, interactivity and advancement of this system is significantly superior to traditional multimedia equipment. This system plays a great role in promoting course teaching effect. Therefore, it is hoped that this system can be more applied in course teaching of college architectural engineering specialty.

\section{REFERENCES}

[1] Rosenthal A., Razansky D., Ntziachristos V., "Wideband optical sensing using pulse interferometry," Optics Express, vol. 20, no. 17, pp. 19016-29, August 2012. http://dx.doi.org/10.1364/OE. 20.019016

[2] Zhang F., Zhong H., Chen C., et al., "Brightly Luminescent and Color-Tunable Colloidal CH3NH3PbX3 (X = Br, I, Cl) Quantum
Dots: Potential Alternatives for Display Technology," Acs Nano, vol. 9, no. 4, pp. 4533-42, April 2015. http://dx.doi.org/10.1021/ acsnano. 5 b01154

[3] Hartmann T., Meerveld H.V., Vossebeld N., et al., "Aligning building information model tools and construction management methods," Automation in Construction, vol. 22, no. 3, pp. 605-613, March 2012. http://dx.doi.org/10.1016/j.autcon.2011.12.011

[4] Fonseca D., Martí N., Redondo E., et al., "Relationship between student profile, tool use, participation, and academic performance with the use of Augmented Reality technology for visualized architecture models," Computers in Human Behavior, vol. 31, no. 1, pp. 434-445, February 2014. http://dx.doi.org/10.1016/j.chb.2013. $\underline{03.006}$

[5] Tong Y.H., "Prospect of application of real 3D display technology in real-time manifestation of landscape environment," Design Art Research, vol. 6, no. 2, pp. 33-36, April 2016.

[6] Dong C.H., "Research and application of virtual reality technology in virtual reality technology course teaching," China Education of Light Industry, no. 4, pp. 52-55, August 2015.

[7] Ye X.T., "Analysis on application of 3D laser scanning technology in ancient building surveying and mapping," Urban Geotechnical Investigation \& Surveying, no. 4, pp. 8-11, August 2014.

[8] Zhang H., "Design of Informationized Teaching for BIM-Based Architectural Courses," Journal of Shazhou Polytechinical Institute of Technology, vol. 17, no. 2, pp. 37-40, September 2014.

[9] Nambisan S., Agarwal R., Tanniru M., "Organizational Mechanisms for Enhancing User Innovation in Information Technology," Mis Quarterly, 23(3):365-395. September 2015. http://dx.doi.org/10.2307/249468

[10] Wang Q., Fan L., Wu X., "Research on the New Airplane Develop System Based on 3D-digital Technique and Multi-companies Collaboration," Procedia Engineering, vol. 99, pp. 101-110, December 2015 .

[11] Kim H.C., Lee C.S., Choi J.H., "A Study on Real-Time Position Analysis and Wireless Transmission Technology for Effective Acquisition of Video Recording Information in UAV Video Surveillance," Journal of Korea Multimedia Society, vol. 18, no. 9, pp. 1047-1057, September 2015. http://dx.doi.org/10.9717/kmms. 2015.18.9.1047

\section{AUTHORS}

Liming Bo (corresponding author) is a Doctor of School of urban design, Wuhan University, Wuhan, China. His research interests include City Planning and Ecological Architecture.(blm105@126.com)

Kanhua $\mathbf{Y u}$ is an Associate profession of School of Architecture, Chang'an University, Xi'an 710061, Shaanxi, China. His research interests include City Planning and Micro-video Course. (yukanhua@yeah.net)

This work was supported by National Natural Science Foundation of China (51378067), Social science fund of Shaanxi Province (213041140109) and Basic scientific research projects of Central University (310841155033) for this work. Submitted 07 August 2016. Published as resubmitted by the authors 13 September 2016. 